\title{
Aspectos de la organización del Segundo Viaje de Colón
}

POr B. T.F. POOLE

La elección de Cádiz como-punto de partida para el segundo viaje de Colón indica plenamente que este iba a ser empresa del Estadoly no particular. La costa occidental de Andalucía constituía el centro marítimo principal del Reino de Castilla pero la selección de Cádiz, que no era la más obvia, se explica por el hecho de que este puerto, aislado en el punto de su península solitaria, podía fácilmente sujetarse a los reales controles ${ }^{(1)}$. Además en ese entonces perteneció a la Corona, habiéndose reintegrado al patrimonio real en Enero de 1493, después de la muerte, sin heredero directo, de su Duque Don Rodrigo Ponce de León $\left({ }^{2}\right)$.

Hay que anotar que cuando en 1495 la Corona modificó las restricciones sobre el comercio particular con las Indias siguió exigiendo que las embarcaciones se limitaran a este puerto de fácil superintendencia, del cual todos los viajes de Colón comenzarían $\left({ }^{3}\right)$. Cádiz se mantuvo como el puerto oficial para las Indias hasta 1503, cuando con la maquinaria

(1) Girard, Albert: Le Commerce Francais a Seville et Cacilx temps du Habsbourg. París,

(2) Pulgar, Fernando del. ${ }^{\circ}$ Crónica de los Reyes Católlcos. Ed. J. de Mata Carriazo, Madrid, 1943. p. 547.

(3) Colección de Documentos Inéditos del Real Archivo de las Indias. 2 series, Madrid, 1864-1884. (D.I.I.) E. 24, pp. 30-37, (30.v.95). 
de los reales controles bien establecida, se permilió que Sevi. lla asumiese este papel (4).

Sin embargo, no fue en Cádiz sino en Sevilla que se esta. biecieron Colón y el oficial real encargado de la admininistración de los asuntos de las Indias, Don Juan Rodríguez de Fonseca. La capital comercial del Sur de España of recía muchas ventajas de orden práctico como centro desde el cual poder organizar la expedición. Sevilla era la "ILLAVE DE ANDALUCIA" $\left({ }^{5}\right)$. El mercado y el punto de enfoque de una región extensiva y populosa. Desde la época de su reconquista por Ferrando el Santo, la ciudad habia quedado establecida como el puerto naval principal de Castilla, como resultado de su situación geográfica, 57 millas tierra adentro en un rio de marea. Por otra parte ya existian en Sevilla interćs y experiencia en la organización de armadas para el Atlántico, interés y experiencia ejercidos en la preparación de flotas dedicadas a la concuuisia de las islas Canarias y en el comercio con la Mína del Oro $\left({ }^{6}\right)$.

A Fonseca y su séquito de oficiales reales la ciudad ofreció un modo de vivir muy distinto al de una corte itineratia, viajando constantemente por caminos malos, y sujeta constantemente a alimentación y alojamientos de cludosa calidad, en aposentos destartalados y estrechos. Presentaba un enorme contraste con la ciudad de Sevilla, afamada por sus calles bien pavimentadas, por su fino pan, considerado como el mejor de España, y sus palacios de mármol entre ellos el Alcázar Morisco, residencia ocasidnal de fos monaudasal las murallas de la ciudad con una circunferenciaindel intre 4 so 5 millas, formaba un circulo casi perfecto en la orilla oriental del ancho Guadalquivir y encima de ellas se levantaba el perfil de la inmensa Catedral, todavia por terminas en esos días, contigua a su majestuosa torre que desde la época de los moros había dominado la campiña circumambiente sirviendo de hito a los viajeros $\left({ }^{7}\right)$. Un acueducto romano de una milla de largo, traía agua abundante a la ciudad, cuyas numerosas fuentes y jardines ordenados de naranjos, limones y palmeras, templaba el calor del verano. Tan bien adaptadas al clima eran las casas, que Fernando solía decir que el Verano debía pasarse en Sevilla y el Invierno en Burgos $\left({ }^{8}\right)$.

(4) Girard. loc.cit. Shafer, Ernesto: El Consejo Real y Supremo de las Indias. Sevilla

(5) Munzer, Jerónim I,pl0ss, II, p350ss.

y Portugal, Madrid, 1952. (Viajes Viaje.. Pub. en: Viajes de Extranjeros por España

(6) Navarretc, Don Martín Fiajes E. P.) 1,372 .

Buenos Aires, 1945. II pp. 450.454: Colección de los Viajes y Descubrimientos,

(7) Munzer, loc. cit. El médice 450.454

(8) Navagero, Andrés. El médico alemán visitó Sevilla en 1494.

ciano a Carlos V estuvo en Sevillaña (Vlajes E. P.) I p851. El embajador vene- 


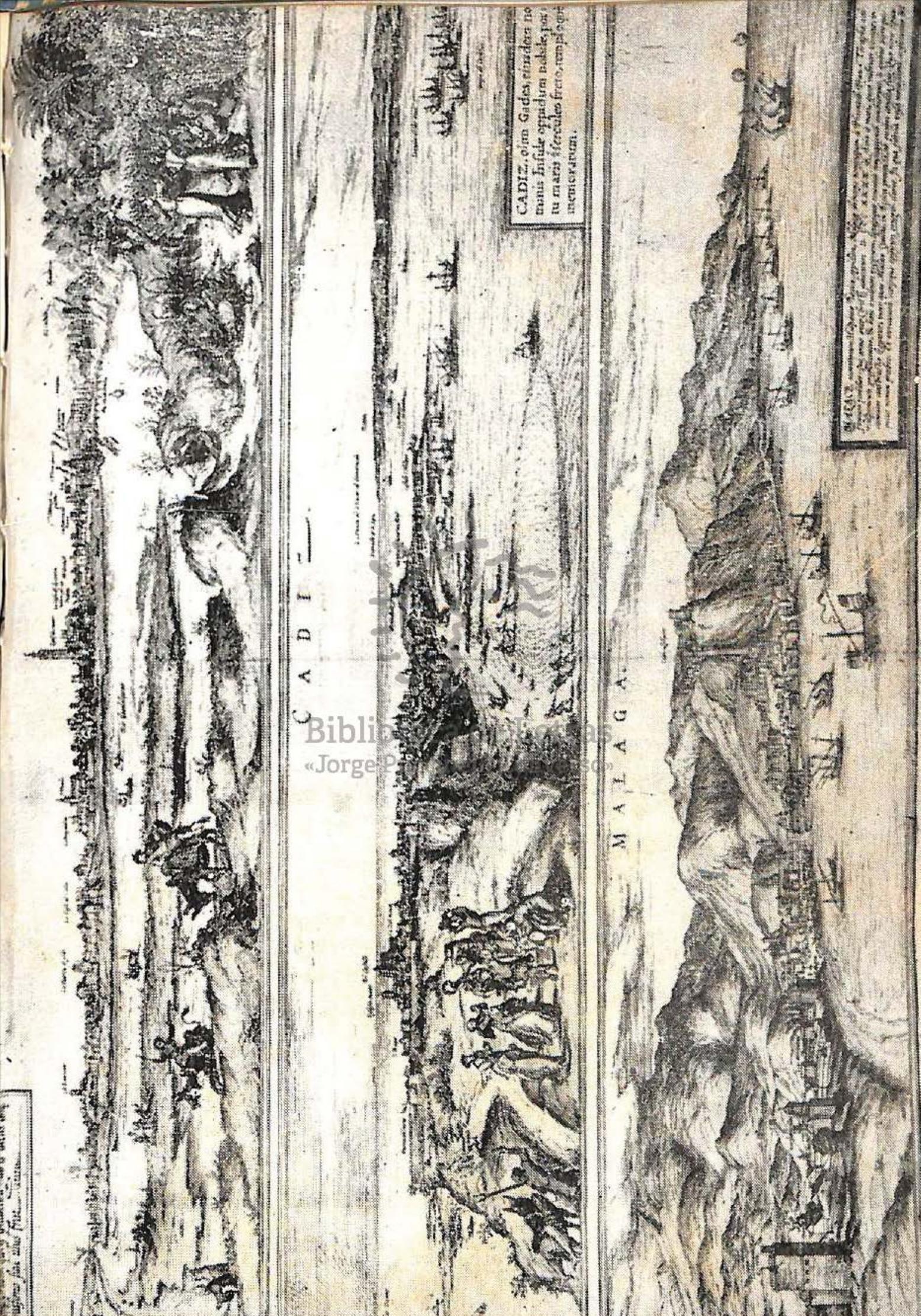


La ciudad era gobernada por un oficial nombrado por la Corona, cl Asistente, en esta época, cl Conde de Cifuentes, Juan de Silva, Alférez de Castilla, miembro de una de las familias más poderosas del Reino, y veterano de las guerras contra los moros y Portugal.

El eje comercial de Sevilla era "LAS GRADAS", la terraza pavimentada que rodeaba la Catedral, donde los mercaderes y los hombres de negocios se reunían diariamente para pasearse y negociar. Por lo tanto fue aquí y en la plazoleta al extremo sur de la Catedral que se organizaba durante los primeros años el tráfico con las Indias $\left({ }^{9}\right)$. Antes de la construcción de la casa de la Contratación en 1503, Fonseca llevaba a cabo negociaciones importantes en su propia casa en la collación de Santa María $\left({ }^{10}\right)$, el barrio próximo al río e inmediatamente al sur de la Catedral, por cuya Patrona había sido nombrado. Este distrito el mejor de Sevilla, incluía el Alcázar y el privilegiado barrio de la Mar, el cual situado entre la Catedral y los almacenes portuarios podría proporcionar una residencia conveniente para un hombre como Fonseca, quien ahora como arcedeano de la Cátedral y funcionario real, ejercia cargos en ambos lugares ( $\left.{ }^{11}\right)$.

Entre la llegada de los oficiales reales en Sevilla y la salida de la flota el día 25 de Setiembre de 1493, transcurrieron poco más de tres meses, poco tiempo para la organización de una empresa tan grande y compleja, La ansiedad de los Monarcas acerca de-la-rivalidad portuguesa proporcionaba el estímulo necesariơopara estä hazaña administrativa $\left({ }^{12}\right)$. Esta ansiedad también explica el hecho de que la flota fuese diseñada no para colonizar, como se ha creído, sino para la guerra, hecho que tendría una influencia profunda en los sucesos inminentes en las Indias.

El carácter bélico de la expedición se demuestra no sólo por la clase de abastecimientos que se embarcaron sino también por la elección de barcos. Aunque faltan detalles exactos se sabe que la flota de 17 embarcaciones incluía 12 carabelas y solamente 3 naos, transportadores de carga pesada $\left({ }^{13}\right)$. Estas fueron diseñadas para la lucha y persecución, y como explicó a los monarcas el secretario real Hernando de Zafra, por esta razón convenían más carabelas y no las torpes y pe-

(9) Ibid. p849

(10) Nava-rete, II p289.

(11) González: Sevilla. I p345 et sce.

(12) D.I.I. t.30, pp216.18; t.21, pp 374.6; t.30, p617; t.30 p179s; t.38, p200ss

(13) Ballesteros y Beretta, Antinio de. Historia de América, Barcelona, 1945 (H.A.) II pp159.61. 
sadas naos para la amada (*). Lat llota que se juntó era, pues, una flota de guerra, " fue tripulada por 1200 "HOMBRES DE GUERRA"o puco mats, en lats palabras del cura De los Palacios, por cuyo pueblo pasarin los expedicionarios en su camino a Caidi\% (is). Las Casas habla de 1500 hombres, "LA MAYORIA CON SUS ARMAS", ("), "Martyr (1") de 1.000 hombres armados.

La acumulacion de abastecimientos, puesta en marcha en mayo de 1493, presento problemas cura sulución apenas se habia conseguido en el ticmpo disponible sin la larga experiencia de la gucrra contra los moros ( $\left.{ }^{18}\right)$. La complejidad de la tarea que confrontaron Forseca y los oficiales reales queda demostrada por el volumen $y$ la varicdad de abastecimientos que se empenaron ahora en amontonar, abastecimientos que a primera vista parecen desmentir la observación de Carlos Pereyra, que las Indias fueron conquistadas por hombres quese la pasaban a dieta de tocino y yuca. Los víveres precisos para una expedición de 1,000 hombres que se prepararían en $1494\left({ }^{19}\right)$, incluian quintales de moslaza, 3 docenas de lámparas de vidrio, 5 docenas de orinales empaquetados en paja, 20 docenas de anzuelos surtidos, 3,000 libras de almendras, entre una gran cantidad de otros articulos variados. Un inventario de provisiones pow Nevar en 4 carabelas en el año 1495 $\left.{ }^{20}\right)$, especifica:

150 cahices de tnigo (el cahiz cra una medida de áridos equivalente a 430 litros aproximadamente).

50 cahices de Jcebada. ccinelli Conversom

60 pipas de vino.

10 barriles de vinagre.

650 costilleras de tocino.

50 quintales de higo.

30,000 mvds. de pescado salado.

30 cahices de judías y garbanzos.

360 quintales de pescado y azúcar, arroz y almendras.

(14) Zafia a RR. CC. Sin fecha pero su contenido indica inosto de 1493. Colecclóin de Documentos Inéditos para la Historia de España, Series I-III. Madrid. (D.I.E.) E.
XI. plo548.52

(15) Berna

Españoles. Andrés de: Historia de los Reyes Católicos pub. en Biblioteca de Autores

(16) Las Casas, Bartolonic Madrid, 1953. p.660. (17) Martyr de A Madrid, 1957) Historia de las Indlas. (L.C.H.G.) (Pub. en B.A.E. Vols

Vols. IX-XII de D.I. E.. Madrid 1053-7 tracl. por José López de Toro. (Pub. en

(18) La maestría de los españoles en la or ornizacićn p250. va tierra fine de los españoles en la, ormizacićn de operaciones combinadas par max

(19) CCIV, CCVIII, CCIX.

(20) D.I.I. 21 pp474ss. I.vii.94 
Se llevó además una variedad de abastecimientos misceláneos, como cáñamo, lona para hacer velas, semillas, y una pequeña cantidad de ganado $\left({ }^{21}\right)$.

Muchos autores, siguiendo a Las Casas, han culpado a Fonseca por haberse demorado adrede en el despacho de las flotas de Colón, pero esta acusación no toma en cuenta el hecho de que los primeros meses del verano, cuando las condiciones climáticas favorecían la navegación, eran por otra parte los peores para la acumulación de víveres. Así es que en éste o el siguiente junio los oficiales de Fonseca le informaron que en ninguna época del año sería más difícil el cumplimiento de sus órdenes, que el precio del pan estaba subiendo y seguiría subiendo hasta la siguiente cosecha a fines de julio, y que la harina de trigo era tan escasa que ya se la mezclaba con cebada. Asimismo informaron que el vino, el tocino y el arroz también se encontraron "al final de su año", costosos y difíciles de conseguir. En tales circunstancias, el descubrimiento, la compra y el transporte de las provisiones principales apenas podrían haberse efectuado mejor ni más rápidamente $\left.{ }^{(22}\right)$.

La cosecha de 1492 había sido buena pero, a pesar de esto la cantidad de trigo que se apartó para la flota hacía peligrar la economía de la región, en la opinión de Hernando de Zafra. Este oficial, franco y no muy amigo de la empresa de las Indias, se queió ia los Reyes en agosto, manteniendo que en asignar a las flotas las tercias de la diócesis de Sevilla $\left({ }^{23}\right)$, habian privado â las ciudades lde la Costa de sus acostumbrados abastecimientos de harina, y que si se tentaba rectificar esta deficiencia trayendo harina de otras partes subiría el costo del pan ${ }^{(24)}$. Sin embargo el pan y los otros abastecimientos parecen haber sido adecuados para la demanda sin que los precios quedaran mayormente afectados $\left({ }^{25}\right)$. Pero a pesar de esto es bien claro que Fonseca y sus asociados cumplieran sus cleberes ante la hostilidad del pueblo y de los oficiales locales. La costumbre de la Corona de otorgar cartas de aposa-

(21) Aparte de aves (50) no se llevó más de seis de minguna otra especie. Esto se contrasta con la flota que llevó Juana y 3.500 hombres a Flandes en 1496 y que cargó en 20 embarcaciones enormes cantidades de víveres entre ellos 200 ovejas, 20 vacas, 100 gallinas - todas vivas- 10.000 huevos y 150.000 sardinas saladas. C.D.E. VIII ppS $/ .548-50$.

(22) Carta a Fonseca de los abastecedores de la armada con fecha 25 de junio, sin año. Archivo de Simancas, Est. Leg, 372 fo. 110 .

(23) Las tercias, una parte de los diezmos eclesiásticos fueron concedidos originalmente por el Papa para los gastos de la Guerra de G:anada, y renovado sin término en 1494 para la cruzada contra los moros de Africa. Historia del Rey Don Hernando, Jerónimo Zurita, Zaragoza MDLXXX. V.fo.496.

(24) Zafra a Reyes. 12.viii. '93. D.I.E.. XI pp. 524-32.

(25) Vea también memorial sobre la situación en Granada. D.I.I. LI pp..115-19. 
miento exigiendo que se diese a los portadores alojamiento a un precio razonable, era una causa constante de resentimiento, y muchas de estas cartas fueron otorgadas a los oficiales que viajaban a Sevilla. De la misma manera los manclamientos a los oficiales de Aduana que diesen paso libre a los efectos destinados para las Indias causaron y causarían, igual resentimiento, siendo cumplidos de mal grado a pesar de repetidas amonestaciones reales $\left({ }^{26}\right)$. El 23 de cibril de 1497 se expidió una cédula prohibiendo a todas las autoridades de España que levantaran los precios de géneros comprados para las Indias $\left({ }^{27}\right)$. Y los aduaneros de Cádiz y Sevilla recibieron otra prohibición más contra la posición de derechos arancelarios en los efectos destinados a las Indias o que de alli vinieran $\left({ }^{25}\right)$. La oposición popular a las exportaciones de víveres era muy natural en esa época y continuaría por varios años causando rencores y hasta violencia $\left({ }^{29}\right)$.

Los preparativos para el segundo viaje de Colón sufrieron poco de la oposición local, aunque pronto demostraría la ciudad de Sevilla su afán de controlar el comercio y hasta la Legislación de las Indias $\left({ }^{30}\right)$.

Este afán, tan característico de las tendencias centrifugas del español, de su búsqueda incesante para la autonomía regional, si no personal, daria en los años venideros trabajo bastante a los oficiales encargados del mantenimiento de la soberanía real en España misma y en las lejanas Indias. Pero por el momento el control de dos preparativos dyla iniciativa en la empresa de las Inclias, quedaronlfirmemente, en manos de los oficiales reales.

(26) 23.V. '93, D.I.I. t19 p.507s, (Andalucia) 26.x.'93; t21, p.337 (Castilla); 26.v.993 t21 p.492s. (Valencia); 18.viii.'94, t38, pp.306ss. (Sevilla): 11 . ix.'94, t.30 p. $312 \mathrm{~s}$ (Sevilla). Cádiz): 16.ix.'94; t.38, p.294s. (General); 8.x.'94, t.38, pp.306-ss

(27) Ibid, t.36, pp.143-5.

(28) Ibid. t. 36, pp. $146-8$

(29) Real Cédula del 5 , vi.1512. Ibid. Serie 2, I.IX, p.1 